Library Acquisitions: Practice \& Theory, Vol. 22, No. 4, pp. 393-407, 1998.

0364-6408/98 \$19.00 + .00. doi:10.1016/S0364-6408(98)00093-3

Copyright $@ 1998$ Elsevier Science Ltd. All rights reserved.

http://www.sciencedirect.com/

http://www.sciencedirect.com/science/journal/03646408

PII S0364-6408(98)00093-3

1996 LAPT RESEARCH AWARD

\title{
EFFECTS OF SERIES AUTHORITY CONTROL FOR ACQUISITIONS
}

\section{TSCHERA HARKNESS CONNELL}

Assistant Professor, Kent State University, School of Library and Information Science, Columbus Campus, 124 Mount Hall, 1050 Carmack Road, Columbus, OH 43210

\begin{abstract}
This study examines the effect of eliminating series authority control on the receipt of unintended duplicates, specifically in the context of approval plans. Random samples were drawn from two large plans at the Ohio State University Libraries (OSUL). Data were gathered from the approval plan vendors' records, bibliographic records, Library of Congress series authority records (for items with series), and the physical items of OSUL-owned titles in each series. Data were also gathered from approval plan vendors regarding their reliance on nationallevel authority work for purposes of identifying items with series. The data from records were used to determine the degree of variance among multiple sources of series information. The results show that 5,838 series items received by OSUL through these two approval plans in FY1993/94 would not be under series control if national-level efforts of control were not in place. Approximately 1200 of these have series statements that do not match with one or more series statements found on items already in the collection.
\end{abstract}

\section{INTRODUCTION}

In 1993, the Library of Congress (LC) proposed to discontinue most of the series authority work it now performs. The proposal was a result of a desire to simplify cataloging operations and reduce arrearages at LC [1]. Reactions were numerous. AUTOCAT, a cataloging listserv, posted several official responses from institutions. Individuals also contributed views. Many called for research to look at the effect on patrons and staff of having no series authority control. After much discussion, Sarah E. Thomas, Director of Cataloging at LC, announced on November 4, 1994, that the Library of Congress would continue to provide added entries and series authorities. Included in the remarks was the statement that "[r]espondents made it clear that acquisitions and collection development activities would be adversely impacted ....” [2]. The research reported here examines series authority control in the context of acquisitions.

\section{REVIEW OF THE LITERATURE}


Determining whether to maintain authority files depends on whether users make use of the references provided through authority work, the expense of maintaining the files, and the effect on various library services if the files are not maintained. This section discusses the literature in the context of these three issues.

A major purpose of authority control is to provide references that will lead the user from terms that he or she enters to the terms used by the designers of the database, if different. Several authors have studied patron and/or staff use of cross references for name headings [3,4] and for subject headings [5]. In a 1995 article, Wilkes and Nelson examine subject searching in two catalogs, one with authority control and one without. All searches that retrieved no hits in the catalog without authority control were searched in the catalog with control. Of the 142 searches that appeared to fail in the catalog without authority control, 105 (73.9\%), would have "retrieved at least one, and often many records if a link had been provided between the term chosen by the user and the term used by the system" [6]. Other writers also have called for more linkages. At the 1994 American Library Association Conference, Snavely and Clark, both reference librarians, discussed the problems of users' searching for the abbreviations of serial titles that they find in indexes to periodicals, and called for more linkages between the abbreviated forms and the full forms of titles used in our catalogs [7].

Only one study was identified that dealt specifically with the use of cross references for series. McCurley and Weisbrod examined 29 months of patron transaction logs to determine the use of cross-references for series title searching at Auburn University [8]. At the time of their data gathering in 1994, the Auburn University library had 24,224 series authority records online; 12,385 (51.13\%) of the records contained cross-references [9]. After eliminating from discussion the records for untraced series, the authors reported on the distribution, the frequency, and the subject areas [10] of the "redirects," that is, instances when the user followed a cross-reference during the time of the study.

McCurley and Weisbrod noted that the number of redirects rose as the number of crossreferences in the database increased, and concluded that patrons and staff not only encountered the cross-references, but actively followed them [11]. They also noted that most titles appearing in the study were redirected by a cross-reference only once and that cross-references for series in science and technology were more heavily used than for other subject areas [12].

An administrative issue of authority control is the amount of time and expense required to maintain authority databases. Profiles of the characteristics of institutions' authority files give insight into the amount of work required to maintain the files. McGrath discusses one institution, the University of Buffalo. Even though the University of Buffalo libraries outsourced the creation of authority records in preparation for their migration to NOTIS, McGrath found that $12.5 \%$ of the provisional records in the sample did not match the national authority file and that $52.4 \%$ of the serials in the sample needed cross references. These figures meant that considerable in-house authority control effort was still required [13].

Profiles of the national resource authority file (NAF) which the Library of Congress is responsible for maintaining, present an even more graphic description of the resources needed for authority control. In a 1992 article, Calhoun and Oskins present the rates and types of changes faced by LC in keeping the national resource authority file current [14]. During a 30-day period in 1991, OCLC received from LC an average of 1,338 changes to the NAF per day. Of these changes, 807 (60\%) were new records, 506 (38\%) changed records, and 25 (2\%) deletes. The authors do not indicate what proportion of the new records and deleted records were series authority records (SARs), but they do discuss the machine readable cataloging (MARC) fields 
that were revised in the records that were changed. Because current cataloging rules give emphasis to title main entry for series, most of the changes to series names will appear in the uniform title (130) field. Of 4,732 changes made to the 1 XX fields over the 30-day period, 415 or $8.8 \%$ were made to the 130 field. Overall, the figures illustrate the dynamic nature of the LC authority files. The authors conclude that "[i]t is safe to assert that if it is not kept up to date in some manner, inaccurate and conflicting headings will accumulate rather rapidly in a local system file, even one that has been cleaned up and brought into conformance with the LC NAF and SAF [subject authority file] before being loaded” [15].

Kuhagen also discusses the national resource authority file. She presents the data content standards for series authority records including policies for when a series authority record (SAR) should be created, under what conditions title variations and/or title changes should be represented, the level of record created, and some of the specifics of the guidelines for numbers of authority records and types of references to be created that are contained in the Library of Congress Rule Interpretations [16]. Kuhagen explains "that references in the SARs fall into four categories: 1) from the form not chosen as main entry; 2) from variant forms of titles; 3) to earlier and later headings; and 4) and from the pre-AACR2 form [17]. Kuhagen notes that the NAF is the Library of Congress's authority file; LC has no other. She makes the point that since AACR2 guidelines for creating references are independent of local processing practice, and because so many libraries depend on the NAF, LC has the responsibility of maintaining records that do not necessarily reflect the Library's in-house handling of the series.

Obviously, because of the degree of LC's contribution to national and international authority control efforts, a major change in LC policies has enormous impact on the operation of other libraries. The quantity of records requiring maintenance alone, as illustrated by the figures of Calhoun and Oskins above, indicate the resources required for a centrally guided national authority control effort. If LC had implemented its proposal to eliminate most of its authority work for series, then individual libraries would have been faced with the decision of whether to follow LC's lead. During the 1994 annual meeting of the National Serials Interest Group (NASIG), Geer-Butler and McKay presented a study of cost factors involved in series authority work at Trinity University. The researchers demonstrated that "decreased authority work by the Library of Congress will result in cost increases at other institutions. If series work is diminished or abandoned, the result will be decreased efficiency and productivity as materials will be processed slower and duplicate purchases will increase” [18]. Some of the institutional responses to the LC series proposal raised the issue of the costs, on a national scale, of duplicated authority work among institutions. However, most libraries indicated that they really would have no choice but to follow LC in abandoning series authority control. These libraries made it clear that they do not have the resources to take over series authority control. Renette Davis, Senior Serials Cataloger of the University of Chicago, although responding on the behalf of her institution, could have represented many libraries when she wrote:

"It is clear that if LC adopts all or part of this proposal as policy, The University of Chicago's four cataloging units . . . will have to follow suit, for both original and copy cataloging. In the Cataloging Department, we have tied our series practices very closely to those of the Library of Congress, with regard to both form of names and treatment.” [19]

The final consideration in maintaining authority files is the effect on various library 
services if the files are not maintained. In preparing its response to the LC proposal, the University of Chicago performed a small study on loss of collocation of series if series authority work is not done. Cataloging staff examined 132 incoming volumes with series and found "that in $36 \%$ of the cases, there would be a loss of collation in our catalog if authority work were not done, because a variation in series title on one of the pieces would not collocate with other entries for that series in the online catalog” [20]. The University of Chicago Cataloging Department followed this study with a brief survey of acquisitions, collection development, and reference staff to determine how diminished authority control for series would affect the work in these areas. The report concludes that, in their library, there will be a workload shift from original cataloging to copy cataloging, reference and inter-library loan activities.

Despite the calls from the field for more research, made at the time of LC's initial announcement, very few articles have been published five years later that specifically address issues of series authority control as it relates to non-cataloging functions of the library, and particularly to acquisitions and collection development. Authority control is useful for collection development and acquisitions to the degree that it assists staff in acquiring all the items desired in a series and that it prevents the acquisition of unwanted duplicates. The issue of duplication is discussed in articles that compare standing orders and approval plans as methods of acquisition. One article discusses the compatibility of the two methods from the point of view of the vendor [21]. Others evaluate the effectiveness of approval plans in comparison to standing orders from the library point of view [22,23,24]. Wilkas reports on one institution's acquisition department's efforts to record online series data that are helpful to patrons and staff [25]. McKay and Geer discuss series authority records in an integrated system as an illustration of one means to enhance catalog effectiveness for all users, but especially for library staff [26]. Other than this illustrative article, no articles were identified that examined the value of series authority control to acquisitions and collection development outside the context of a comparison of methods for obtaining materials.

This study was designed to fill that gap by examining the question: To what extent (if any) will eliminating series authority control at the national level increase the potential for duplicates? Specifically, the issue is examined in the context of approval plans at one large university. What are the variances between the records currently supplied by approval plan vendors and the series titles now used in our catalogs? How frequently do variances occur in how the series is presented among different items in the series? How frequently are these variances (both approval plan record variances and item variances) captured in the form of cross references on national-level authority records? How many items are likely to be affected by variances in a large library catalog? The answers to these questions indicate the extent of variance in vendor records, and on physical items. Taken together they present the extent of the series name inconsistencies that could occur in a single year of a large collection and catalog if no NAF was available and the library did not perform series authority control locally.

The importance of vendor operations to this issue is acknowledged. In 1987 Alessi wrote that:

"Series control is an integral part of every approval vendor's operation. It is critical for the approval vendor to identify new titles in series as well as titles in ongoing series, if the approval plan is not to interfere with a library's standing orders.” [27]

It is possible that series control is monitored sufficiently by the vendors for purposes of 
preventing unwanted duplicates. It is also possible, however, that vendors depend upon nationallevel authority records as libraries do. Although the focus of this study is on the effect of eliminating national-level series authority control on the monitoring of series within the library, the issue of whether current bibliographic control efforts of the approval plan vendors are enough, at least with respect to acquisitions, is also discussed.

\section{METHODOLOGY}

The study involved an examination of the receipts for the fiscal year 1993/94 from two large approval plans at The Ohio State University Libraries (OSUL). A random sample of 382 items was drawn from 17,197 titles received from Baker \& Taylor; also, 335 items were drawn from 1,141 titles received from Harrassowitz. The sample sizes were determined using a table for sample sizes for finite binomial populations [28]. The sample sizes achieve, with 95\% confidence, a statistical precision of $\pm 5 \%$ in the estimated proportion.

For all sampled items, data were gathered from the individual item record provided by the approval plan vendor, and the matching LC bibliographic record from the OCLC database. In all cases, Library of Congress records were chosen, if available. For those items that were identified as belonging to a series, additional data were gathered from the Library of Congress series authority record (SAR), and from physical items of OSUL-owned titles in each series. The examination of physical items in the series involved determining the location of any series statement(s) on the items. Any variations of series titles were checked against the see from reference (4XX) fields of the SARs to see if references were provided from the variants to the established form of the series title.

Series information from the vendor's individual item record was compared with the established heading field in order to determine the degree of variance between the two when a national authority resource file is available. Series statements found on the physical items were compared with series authority records to determine the degree to which varying statements on the items were linked through authority control. As discussed later, this comparison indicates potential difficulties in identifying items with series, in a database without control.

Part of the 1993 LC proposal was to discontinue making series authority records for numbered series, classed separately. Therefore, the series authority records were examined to determine the proportion of series received on the approval plans that were: 1) numbered; 2) currently traced by LC; and 3) currently classed separately by LC. The data on the series authority records also reveal whether the title on the record represents a monographic series, a multi-part item, or if it is considered a series-like-phrase by LC. Collectively, these data give an indication as to how many series items received by OSUL through approval plans would no longer be under nationally coordinated authority control if LC had ceased its efforts in this area. The data indicate the size of the task for OSUL to maintain, alone, an internal system of series authority control. These data were analyzed using a PC-version of SAS Statistical Software.

In addition, information was sought from the acquisition and cataloging staff of OSUL, and four approval plan vendors about their internal processes for series authority control. Questions were designed to determine the degree that OSUL and vendors rely on LC's authority work in the process of identifying series. OSUL acquisitions staff were asked if they verify the series information they receive from vendors, and if so, how? Do they check series statements on items received against their catalog? the NAF? and/or their own internal files? Cataloging staff were asked if they rely on LC's authority work in the process of establishing a series heading for use in the catalog. 
After a brief e-mail introduction explaining the project, representatives of the Academic Book Center, Baker \& Taylor, Harrassowitz, and Yankee Book Peddlar were asked if their respective companies rely on the national NAF (LC's) for series verification. If the answer to that question was yes, they were asked what they do if no series entry is found in that file for a series in hand, whether their company maintains an authority file separate from the NAF, and if their company ever handles a series differently from the way that LC handles it. The final question asked how their company monitors varying series statements among items in a series. Included with this question was a request for an outline of procedures followed for an item that appears to be in series. In order to clarify this request for a description of procedures, two questions were provided as examples of the type of information sought: 1) If the physical item is not present, what alerts [vendor name] personnel to the possibility that a title might be in series? 2) What kind of follow-through takes place in the identification process? "Vendors were requested to respond by e-mail or, if more convenient, a phone appointment was offered. For all vendors, this initial group of questions was followed by one or two questions to clarify a point or test this author's interpretation of a response.

\section{RESULTS AND DISCUSSION}

Processing of Items with Series by OSUL and Approval Plan Vendors

OSUL. When the OSU Libraries receive an item on approval, it is searched by title in the online catalog, prior to its placement on collection managers' review shelves. Any series title appearing on the approval plan record, or on the title page of the item-in-hand, is also searched. If during the bibliographic search the title of the item is not found, it is assumed that there are no holdings at OSU. Although an extensive bibliographic search for potential series involvement does not occur, if the searcher notices a very similar title in close alphabetic proximity (i.e., on the same screen), this information is noted for review by a collection manager. The collection manager will then make a judgment call on the item. However, because the vendors are regularly provided a list of series and standing orders created from the OSU continuation order files, items with series that might otherwise fit the OSUL's approval plan profiles are eliminated by the vendor prior to shipment. This procedure reduces, greatly, the number of items with series received through approval plans.

After a book is selected for inclusion in the collection by a collection manager, it is sent to acquisitions processing for copy cataloging. The staff member performing the copy cataloging searches for an OCLC bibliographic record that matches the item-in-hand, giving preference to LC records. When a potential match is found, author, title, imprint, physical description, and access points are all compared. Series information is accepted if it is pretty similar. The selected record overlays the order record in the catalog. Any needed authority work is batch processed at a later time by the authority control section [29]. OSU uses the LC authority file and LC authority records for verifying the construction of access points. However, if no LC record is available, any other reasonable record is used. OSU is a NACO (Name Authorities Cooperative) library and so has the training and authorization to add records to the national file.

This description of procedures shows OSUL's reliance upon national-level cooperative cataloging. Even though the authority work does not occur during the initial processing of the receipts from the approval plan, the authority work does occur later in the process. Preference is given to the work of LC and, therefore, the authority efforts of LC greatly influence the form of 
headings in OSU's catalog. For the OSUL, some degree of variance during bibliographic verification of items in an order is manageable and is not likely to result in unintended duplicates. The process includes some insurance. The number of series items received through approval plans is greatly reduced by blocking items that OSU considers continuations, by the collection managers' expertise and experience, and by verification of access points through authority work at a later date.

Vendors. Three of the vendors were able to respond to the author's query. All noted the importance of monitoring series.

"If a library has one vendor for approval plans and another for standing orders, it is critical that the library provide the approval vendor a list of standing order titles to block from coverage. Approximately $30 \%$ of what an approval vendor handles is part of some kind of series, so it's important to correctly identify which titles to block.” [30]

None of the vendors rely on the LC NAF directly; they all work from their own internal files, and from the standing order lists supplied by libraries. One vendor described his company's list as a "function file" rather than an authority file. Vendors agreed that some variation in how a series is cited is workable in the context of fulfilling approval plan orders; and, in fact, they expect LC, publishers, and libraries to cite series titles with some variations.

"As long as we can determine with a fair degree of accuracy that an approval title is already being supplied to a library on a standing order, we don't insist that the series title conform to a specific authority list. Usually, series titles from mainstream presses are cited fairly uniformly by everyone involved. When they are not, we take our best educated guess.” [31]

A couple of the vendors noted that the system seems to work quite well because the prevention of duplicates is considered a strong point of their services. However, it was also mentioned that in a cataloging context, acceptance of variance is a different matter:

“... the expression of a series title in a cataloging record may involve a different set of rules entirely than does the vendor's own database. It is possible to control duplication effectively without using formal cataloging practices-but when delivering cataloging records, such [cataloging] practice is required. ... Thus, the form of a series entry in the vendor's world may depend on its use.” [32]

In this, the OSUL and vendors agree.

Even though the vendors do not rely directly on LC's national authority file (and, in the case of Harrassowitz, the files of the Deutsche Bibliothek, as well), they all use some combination of CIP (Cataloging in Publication) data, LC MARC records, and if available, ISSNs (International Standard Serials Numbers). Harrassowitz reported that approximately

" $50 \%$ of the records we release into our Web Site and into our form selection program have been cataloged in autopsy [i.e., with item in hand]. [For these,] then, there is no problem with series entry.... For the other half of the titles we rely on the most reliable 
sources that we can get, usually the national bibliographies (CIP), and this also should preclude errors in the citation of the series.” [33]

TABLE 1 Series In Approval Plan Samples

\begin{tabular}{lccc}
\hline & \multirow{2}{*}{$\begin{array}{c}c \\
\text { Sample } \\
\text { PLAN }\end{array}$} & Items in series \\
\cline { 3 - 4 } & size & Number & Percent \\
\hline Baker \& Taylor & 382 & 123 & 32.2 \\
Harrassowitz & 335 & 191 & 57.0 \\
TOTAL & 717 & 314 & \\
\hline
\end{tabular}

In order to gain greater understanding of the degree of reliance on national level cataloging, the author asked two of the vendors for clarification. Both vendors acknowledged that although they do not rely on national authority files, they do depend on national-level authority work - through national-level cataloging records. This point is important because if this reliance is representative of vendor practices, then current practice is not enough to cover a loss in national-level authority control - at least in the short term. If vendors found they were shipping unintended duplicates, they could, of course, develop procedures for more extensive authority work. However, the immediate effect of reduced series authority work on the national level would be less certainty in the identification of items with series for vendors and libraries alike.

Description of the Sample

Overall, the Harrassowitz plan provided more items with series. Nearly three fifths of the items from the Harrassowitz sample were part of a series; approximately one third of the items from the Baker \& Taylor sample were part of a series (Table 1). For most series only one item of the series was received during the 1993/94 year: the Baker \& Taylor plan had five series represented by two items and one series represented by three items, but the remaining 110 items each represented a different series. The Harrassowitz plan had nine series represented by two items, one series represented by three, one by four, and one by five items. Series represented by only one item comprised 93.7\% (179/191) of the Harrassowitz sample (Table 2). A total of six items (from both plans) belong to two series.

TABLE 2 Unique Series and Series Represented by Multiple Items

\begin{tabular}{lcccccc}
\hline & \multicolumn{5}{c}{$\begin{array}{c}\text { Number of series } \\
\text { PLAN }\end{array}$} & \multicolumn{5}{c}{ represented by $1,2,3,4$, or 5 items } & TOTAL \\
\cline { 2 - 6 } & 1 item & 2 items & 3 items & 4 items & 5 items & $1-5$ items \\
\hline Baker \& Taylor & 110 & 5 & 1 & 0 & 0 & $123^{\mathrm{a}}$ \\
Harrassowitz & 161 & 9 & 1 & 1 & 1 & $191^{\mathrm{b}}$ \\
\hline
\end{tabular}

${ }^{\mathrm{a}}(110 \times 1)+(5 \times 2)+(3 \times 1)$

${ }^{\mathrm{b}}(161 \times 1)+(9 \times 2)+(1 \times 3)+(1 \times 4)+(1 \times 5)$ 
TABLE 3 Matches of Vendor-Noted Series and Series Authority Records (SAR)

\begin{tabular}{|c|c|c|c|c|c|c|c|}
\hline \multirow[b]{2}{*}{ VENDOR } & \multirow{2}{*}{$\frac{\text { Vendor-noted series }}{\text { no. }}$} & \multicolumn{2}{|c|}{ SAR $1 X X$ matches } & \multicolumn{2}{|c|}{ SAR $4 X X$ matches } & \multicolumn{2}{|c|}{$\begin{array}{l}\text { No match with } \\
\text { SAR records }\end{array}$} \\
\hline & & no. & percent & no. & percent & no. & percent \\
\hline Baker \& Taylor & 112 & 92 & 82.1 & 6 & 5.4 & 14 & 12.5 \\
\hline Harrassowitz & 186 & 148 & 79.6 & 12 & 6.5 & 26 & 14.0 \\
\hline Total & 298 & 240 & 80.5 & 18 & 6.0 & 40 & 13.4 \\
\hline
\end{tabular}

Agreement Between Series Listing on Vendor Record and on NAF Record

Both vendors noted over $90 \%$ of the items with series on their individual item records. Although the Baker \& Taylor records recorded individual items as part of the series $91.1 \%$ of the time (112/123), the vendor was inconsistent in the way that information was provided. For $48.2 \%$ of the items, the series title was found at the end of the title listing for the individual item. The remaining series titles (51.8\%) were found on other parts of the record. For the Baker \& Taylor plan, therefore, it is necessary for staff to search carefully the entire approval plan record for series statements so that series are not missed. Harrassowitz was more consistent. Nearly $100 \%$ of Harrassowitz's notations for series title appeared at the end of the title listings for the individual item. Overall, Harrassowitz identified 97.4\% (186/191) of the items that are part of a series as series items on its records.

Of the 112 series items noted on the Baker \& Taylor records, 92 (82.1\%) matched the established heading field (1XX) on the series authority records, and 6 (5.4\%) matched a crossreference field (4XX) (Table 3). This means that working only from the series information on the vendor record, $\approx 88 \%$ of the items would result in verification during bibliographic searching in a database constructed and maintained in accordance with the NAF. For Harrassowitz items the figures are similar. Of the 186 series items noted on the Harrassowitz records, 148 (79.6\%) matched established headings on the SARs, and 12 (6.5\%) matched cross-references meaning that $86 \%$ of the items would be verified in the process of bibliographic searching (Table 3 ).

The match rate to the established heading for both vendors together is $80.5 \%((92+148) /$ $(112+186))$. If these vendors were suddenly faced with a situation where there was no nationallevel authority effort and, therefore, cross references were no longer available to the library that had depended upon them in the past, the potential number of variances in headings is large. For the Baker \& Taylor plan, the sample of 382 was drawn from a population of 17,197 items received. Items with series numbered 123 or $32.2 \%$ of these. A $20 \%$ non-match rate for OSUL approval plans, means that approximately 1100 series items (17,197 X 32.2\% X 20\%) from Baker \& Taylor, and 130 items (1,141 X 57\% X 20\%) from Harrassowitz, per year, would not match series information on bibliographic records in OCLC. With so many series not matching bibliographic records, there is great potential for not verifying items with series, and for receiving unintended duplicates. Over time, the inconsistencies in series citation practice would accumulate making the identification of series a more complex process. 
TABLE 4 Location of Series Statements on Books

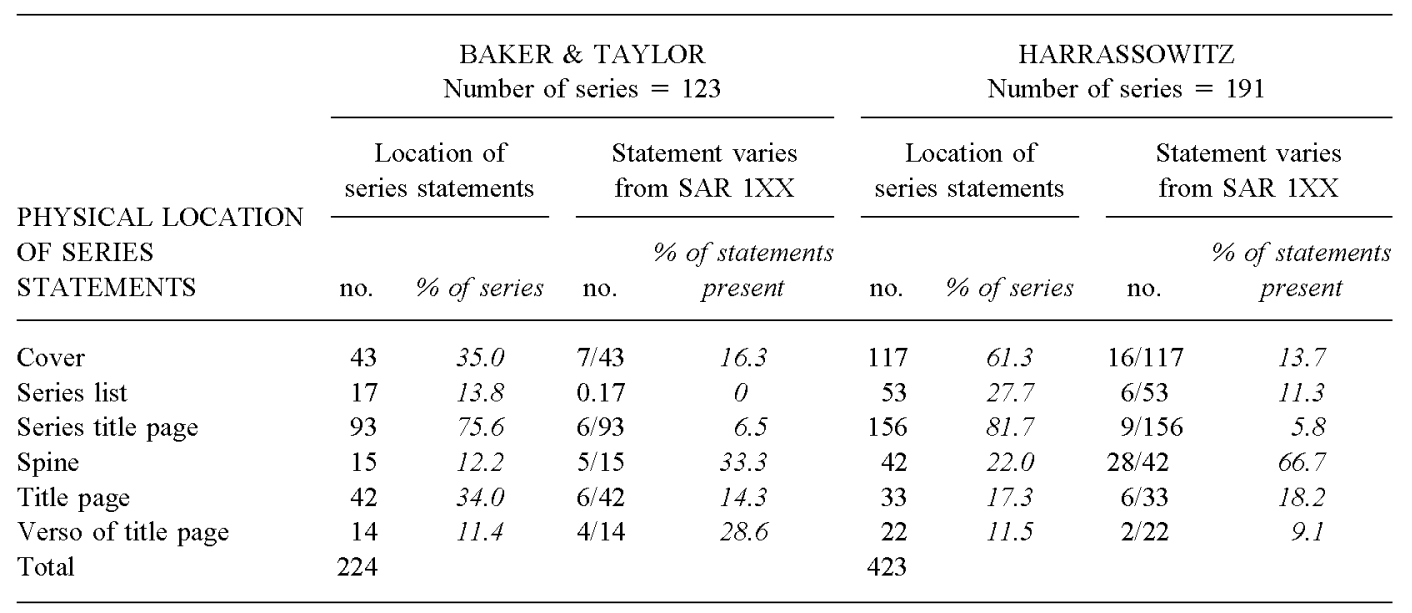

Series Statements on Physical Items

Another issue in considering the need for series authority control is the degree to which series statements vary on a single item in the series and/or among all items in the series. Items from series identified in the sample and owned by the OSUL were checked for the location of series statements and for any variations in how the statements appeared. Each item was examined to see if the series title appeared in some form on the cover, a list at the front or back of the item, a series title page, the spine, the title page of the book, and the verso of the title page. It should be noted that series statements occurring only in cataloging-in-publication (CIP) data on the verso of title page, were not counted. The reason for omitting series fields in CIP data are that if LC were to abandon series authority control, any series statements appearing in CIP data would not be controlled. The data in Table 4 show that many items had multiple indications that they were part of a series. In fact, for Harrassowitz items the number of statements (423) more than doubles the number of series (191). For the books received on both plans, series information was most likely to be found on a separate series title page. As well, the information found on a series title page is the most complete. Not surprisingly, given the limited space available, series statements on the spine had the greatest variation.

In terms of accuracy and efficiency, the best place to find series information is the series title page. However, if there is no title page, a second source must be examined. For Baker \& Taylor, the percentage of series statements that could be found on the cover and the individual title page were almost equal. Because title page information is generally considered more reliable, and because OSUL staff look for series information on the title page, the title page was examined as a second source. For the Baker \& Taylor items, 30 series (24.4\%) did not have separate title pages. Examining the individual item title pages for those 30 series, 22 series statements (73.3\%) could be found, and only one of these varied from the uniform title established by LC. For series from Harrassowitz, both the title page and the cover were checked as possible second sources. Both were checked because statements appeared on the covers for such a high percentage (61.3\%) of series in the sample. For the 35 series that were not represented by separate series title pages, the data from the two secondary sources were almost identical in terms of the provision of series information that matches the current practices for 
TABLE 5 Series Heading Construction and Use (from Series Authority Records)

\begin{tabular}{|c|c|c|c|c|c|c|}
\hline \multirow[b]{2}{*}{ DESCRIPTION OF RECORDS } & \multicolumn{2}{|c|}{$\begin{array}{c}\text { Baker \& Taylor } \\
\quad(n=119)\end{array}$} & \multicolumn{2}{|c|}{$\begin{array}{l}\text { Harrassowitz } \\
\quad(n=188)\end{array}$} & \multicolumn{2}{|c|}{$\begin{array}{l}\text { Both plans } \\
(n=307)\end{array}$} \\
\hline & no. & $\%$ & no. & $\%$ & no. & $\%$ \\
\hline \multicolumn{7}{|l|}{ Record status: } \\
\hline New & 74 & 62.2 & 95 & 50.5 & 69 & 55.0 \\
\hline Revised & 45 & 37.8 & 93 & 49.5 & 138 & 45.0 \\
\hline \multicolumn{7}{|l|}{ Series heading use: } \\
\hline Appropriate as series added entry & 119 & 100 & 188 & 100 & 307 & 100 \\
\hline AACR2 descritive cataloguing rules used & 119 & 100 & 188 & 100 & 307 & 100 \\
\hline
\end{tabular}

establishing uniform titles for series. For 21 series (60.0\%) information could be found on the title page of the book. Four of these were variations of the established headings. For 22 of the series (62.9\%) information could be found on the cover, and five of these statements varied from established headings.

For the 123 items with series from the sample received through the Baker \& Taylor plan, $23(18.7 \%)$ had at least one item with a series statement that did not match other statements found on OSUL-owned items. For the 191 series in the sample of Harrassowitz-provided items, 47 (24.6\%) had items with statements that varied in form. This figure is not as high as the $36 \%$ reported by the University of Chicago, but in contrast to the University of Chicago data which came from all acquisition receipts, the present study examined only titles in series that are received on approval. However, $18-25 \%$ is still quite a bit of variance. Without authority control, there is great potential for recording titles of series in multiple ways, and as multiple forms of titles proliferate, bibliographic verification becomes more difficult.

\section{Description of Series, Series Authority Records, and LC Treatment of Series in Sample}

There were 307 series authority records (SARs) representing the series from both plans (Table 5). Of these, the proportion was nearly equal between records that were new (55\%) and records that were revised (45\%). For the Baker \& Taylor-provided series, nearly 38\% of the SARs were revised; $62 \%$ were new. The division SARs for series provided by Harrassowitz were half and half: half the records were new and half were revised. Because this study examined only SARs, there is no way to tell if these figures are comparable to Calhoun and Oskins report that $38 \%$ of all the NAF records processed by OCLC over a 30-day period were revised. However, both studies illustrate the dynamic nature of the NAF.

Almost all of the series (99.3\%) in both samples are monographic series and multi-part items (Table 6). There is quite a bit of difference, however, between the samples from the two plans in regard to series that are numbered. Only $37.8 \%$ of the series provided by the Baker \& Taylor plan were numbered. That percentage is nearly doubled (77.7\%) for series provided by Harrassowitz. Over half (56.3\%) of the series received through Baker \& Taylor are unnumbered; only $18.1 \%$ of the Harrassowitz-provided series are unnumbered. The LC proposal would have eliminated making series authority records for unnumbered series or unnumbered multi-part items. 
TABLE 6 LC’s Description and Treatment of Series in the Research Sample

\begin{tabular}{|c|c|c|c|c|c|c|}
\hline \multirow{2}{*}{$\begin{array}{l}\text { DESCRIPTION- } \\
\text { TREATMENT }\end{array}$} & \multicolumn{2}{|c|}{$\begin{array}{l}\text { Baker \& Taylor } \\
\quad(n=119)\end{array}$} & \multicolumn{2}{|c|}{$\begin{array}{l}\text { Harrassowitz } \\
\quad(n=188)\end{array}$} & \multicolumn{2}{|c|}{$\begin{array}{l}\text { Both plans } \\
(n=307)\end{array}$} \\
\hline & no. & $\%$ & no. & $\%$ & no. & $\%$ \\
\hline \multicolumn{7}{|l|}{ Type of series: } \\
\hline Monographic & 113 & 95.0 & 183 & 97.3 & 296 & 96.4 \\
\hline Multipart & 5 & 4.2 & 4 & 2.1 & 9 & 2.9 \\
\hline Series-like phrase & 0 & 0 & 1 & 5.3 & 1 & $<0.01$ \\
\hline Other & 1 & 0.8 & 0 & 0 & 1 & $<0.01$ \\
\hline \multicolumn{7}{|l|}{ Series numbering } \\
\hline Numbered & 45 & 37.8 & 146 & 77.7 & 191 & 62.2 \\
\hline Unnumbered & 67 & 56.3 & 34 & 18.1 & 101 & 32.9 \\
\hline Numbering varies & 6 & 5.0 & 5 & 2.7 & 11 & 3.6 \\
\hline Not applicable & 1 & 0.8 & 3 & 1.6 & 4 & 1.3 \\
\hline \multicolumn{7}{|c|}{ LC's series tracing practice } \\
\hline Not traced & 3 & 2.6 & 11 & 5.9 & 14 & 4.6 \\
\hline Not traced 1981- & 1 & 0.8 & 0 & 0 & 1 & $<0.01$ \\
\hline Traced & 110 & 92.4 & 170 & 90.4 & 280 & 91.2 \\
\hline Traced 1967- & 0 & 0 & 1 & 0.5 & 1 & $<0.01$ \\
\hline Traced 1981- & 5 & 4.2 & 6 & 3.2 & 11 & 3.6 \\
\hline \multicolumn{7}{|c|}{ Series classification practice (LC) } \\
\hline Classed together & 7 & 5.9 & 6 & 3.2 & 11 & 3.6 \\
\hline Classed separately & 112 & 94.1 & 182 & 96.8 & 294 & 95.8 \\
\hline
\end{tabular}

Based only on the consideration of whether a series is numbered, the implementation of the proposal would have meant that there would be no national-level authority control performed for one third (32.9\%) of the series items received by the OSUL through these two authority plans.

LC had proposed to continue to make series authority records "for numbered series classified as collections and for numbered, analyzable, multi-part items," noting that these two types of series account for $14 \%$ of all the SARs [34]. The percentage of series received by the OSUL that were classed together (by LC) is much lower. Overall, only 11 (3.6\%) of all the series items from the two approval plans were classed together. 112 (94.1\%) of the series provided by Baker \& Taylor and 182 (96.8\%) of the series provided by Harrassowitz are classed separately by LC. For the OSUL, a decision by LC to perform series authority control only for items which LC classes together would provide very little assistance at all.

Currently, 292 (95\%) of the items received through the OSUL's Baker \& Taylor and Harrassowitz approval plans are traced. A change in policy of the magnitude of the LC proposal would mean that almost none of these items would be traced in the future.

\section{SUMMARY AND CONCLUSIONS}

The two major approval plans used by the Ohio State University Libraries handle many items with series. One-hundred twenty-three (123) or $32.2 \%$ of the 382 items sampled from the Baker \& Taylor receipts (17,197 items) are with series. For the Harrassowitz receipts (1,141 items), 191 (57\%) of the 335 items sampled are with series. In total these figures translate to 5,538 items $( \pm 5 \%)$ with series received through Baker \& Taylor, and 651 items ( $\pm 5 \%)$ with series received through Harrassowitz, annually. Most of the series were represented by only one item in the samples.

Authority control is useful to acquisitions if it assists staff in acquiring all the items 
desired in a series and if it prevents the acquisition of unintended duplicates. A major question in this study was how well do the current services of approval plan vendors assist acquisitions staff in these tasks. In terms of the identifying individual items in a series, the vendors did well. However, the means for indicating this information to the library could be confusing. Titles were often abbreviated or truncated and at least for Baker \& Taylor, the information could be recorded in one of several parts of the vendor record. If a library were depending on vendors for series collocation (to assist in weeding out unwanted duplicates), the consistent placement of the recording of series information would be helpful. As discussed in the section on agreement between the vendor record and the SAR, approximately 20\% (58/298) of all items identified by both vendors as series did not match the headings established for the title of the series as established by LC. Many of the variances were due to the use of abbreviations and truncation of titles by the vendors. For the task of matching, the experienced searcher can still recognize the abbreviated titles. However, if the bibliographic records were themselves not under authority control, matching titles could be more difficult. Vendors, too, rely on national level authority work so that a reduction of the level of cooperative authority work is likely to create more variance on vendor records, compounding the difficulty of verification.

Many of the institutional responses to the LC proposal indicated that if LC were to discontinue providing authority control for series, the institutions would have to follow suit. What is the potential for inconsistencies to occur in the catalog if series authority control is no longer provided? The data from this study indicate that series information appears in multiple locations on many items and that between $12-15 \%$ of these statements vary in form of presentation. The sources most consistent with current policies for heading construction is the separate series title page and the individual item title pages.

Of the 123 series items in the sample of items received through the Baker \& Taylor plan, $23(18.7 \%)$ would not match with one of the series statements found on items already in the collection. For the 191 items with series in the Harrassowitz sample, 47 (24.6\%) of the items contained series statements that would conflict with statements on other items already represented in the catalog. If authority control is not performed, a rate of $18-25 \%$ of items received in a collection the size of OSUL's, represents a considerable loss in collocation of items with series.

One of LC's proposals was to discontinue making series authority records for numbered series, classed separately. The data in Table 6 show that, based on the samples in this study, such an action would eliminate authority control for $94.1 \%$ of the items added to the OSUL's collections through the Baker \& Taylor approval plan, and for $96.8 \%$ of the items received through the Harrassowitz Plan. For the 1993/94 fiscal year, 94.1\% of the Baker \& Taylor items with series added to the OSUL's collections, translates to 5210 items ( $\pm 5 \%)$. For Harrassowitz, $96.8 \%$ of the items with series added to the collections is 630 items $( \pm 5 \%)$.

The proportion (45\%, see Table 5) of revised series authority records encountered for items in the samples shows the dynamic nature of series authority work. Many changes in records are made as a result of new information discovered in processing new items. The fact that nearly half the records consulted for this study had been changed is further indication that without authority control it would become very difficult to be able to identify all items in a particular series. Carol Pitts [Hawks] Diedrichs, Head of the OSUL Acquisition Department, stated in her department's response to the series proposal that:

"no series control means pre-order search will take longer and be less accurate because 
more variant forms of a series will need to be located and evaluated. . . . It is essential to have series control for titles ordered as series and cataloged separately as monographs to ensure all published titles in the series have been received. Lack of series control will result in increased purchase of unintended duplicates.” [35]

The data in this study bear this out. For series received through approval plans, much of the elimination of duplicates occurs prior to receipt of approval plan orders. However, the variance of series information on vendor reports, physical items themselves, and series authority control records indicates that a reduction of national-level authority control would make the verification of series information for all receipts very difficult. Even for items with series received on approval, an 18-25\% variance is substantial in a collection the size of OSU's.

\section{ACKNOWLEDGMENTS}

This research resulted from the 1996 Library Acquisitions: Practice \& Theory Research Award. The approval plan records used in the research came from The Ohio State University Libraries’ Acquisition Department. I especially thank Carol Pitts Diedrichs, Head of the Department, for providing access to these records and for providing contacts to vendors. I also acknowledge Knut Dorn of Harrassowitz, Rick Lugg of the Yankee Book Peddlar, and Bob Schatz of the Academic Book Center for answering my questions about vendor procedures. Thanks, too, go to Marsha Hamilton for answering my questions about the processing of approval plan materials at OSUL.

\section{REFERENCES}

1. Library of Congress. Series Group. “Report (20 Jan. 1994).” Automated Cataloging Discussion Group (AUTOCAT) [Online] Available E-mail: AUTOCAT@ubvm.cc.buffalo.edu (Jan. 20, 1994).

2. Thomas, Sarah E. LC Decision on Series Authorities. Cooperative Cataloging Discussion Group (COOPCAT) [Online] Formerly available E-mail: COOPCAT@nervm.nerdc.ufl.edu (November 7, 1994).

3. Taylor, Arlene G. “Authority Files in Online Catalogs: an Investigation of Their Value.” Cataloging \& Classification Quarterly, 4 (1984), 1-17.

4. Bangalore, Nirmala S. “Authority Files in Online Catalogs Revisited.” Cataloging \& Classification Quarterly, 20 (1995), 75-94.

5. Van Pulis, Noelle, and Lundy, Lorene E. "Subject Searching in an Online Catalog With Authority Control." College \& Research Libraries, 49 (1988), 523-533.

6. Wilkes, Adeline, and Nelson, Antoinette. "Subject Searching in Two Online Catalogs: Authority Control vs. Non-authority Control.” Cataloging \& Classification Quarterly, 20 (1995), 7.

7. Snavely, Loanne, and Clark, Katie. "What Users Really Think: How They See and Find Serials in the Arts and Sciences.” Library Resources \& Technical Services, 40 (1996), 49-60.

8. McCurley, Henry H., and Weisbrod, Elizabeth J. "Use of Series Title Authority Cross-references at a Large University Library.” College \& Research Libraries, 57 (1996), 285-294.

9. McCurley, and Weisbrod. "Use of Series Title Authority Cross references,” 286.

10. The Library of Congress classification (LCC) was used to define the subject categories: humanities (classes A, B, except BF, M, N, P, Z); social sciences (classes BF, C, D, E, F, G, H, J, K, L), and science/technology (classes Q, $\mathrm{R}, \mathrm{S}, \mathrm{T}, \mathrm{U}-\mathrm{V})$.

11. McCurley and Weisbrod. "Use of Series Title Authority Cross references," 293.

12. Ibid.

13. McGrath, Ellen. "Developing Priorities for Authority Work at the University at Buffalo Libraries.” Cataloging \& Classification Quarterly, 16 (1993), 5-23.

14. Calhoun, Karen, and Oskins, Mike. "Rates and Types of Changes to LC Authority Files." Information Technology and Libraries, 11 (June 1992), 132-136.

15. Ibid., 135.

16. Kuhagen, Judith A. "Standards for Name and Series Authority Records.” Cataloging \& Classification Quarterly, 21 (1996), 131-154.

17. Ibid., 150 . 
18. Smets, Kristine A. J. “'Keep Them Doggies Rollin’,” or, Using Series Authority Records to Improve Cataloging and Processing Workflow.“ Serials Librarian, 25 (1996), 278.

19. Davis, Renette. Response to LC series proposal [from the University of Chicago Library]. Automated Cataloging Discussion Group [Online]. Available E-mail: AUTOCAT@ubvm.cc.buffalo.edu (March 29, 1994).

20. Davis. "Response to LC."

21. Alessi, Dana L., and Goforth, Kathleen. “Standing Orders and Approval Plans: Are They Compatible?” Serials Librarian, 13 (Oct./Nov., 1987), 21-41.

22. Kaatrude, Peter B. "Approval Plans Versus Conventional Selection: Determining the Overlap." Collection Management, 11 (1989), 145-150.

23. Rouzer, Steven M. “Acquiring Monographic Series by Approval Plan: Is the Standing Order Obsolescent?” Library Acquisitions: Practice and Theory, 19 (1995), 395-401.

24. Warzala, Martin. “Acquisition of Monographic Series: Approval Plan Versus Standing Order.” Library Acquisitions: Practice and Theory, 15 (1991), 313-27.

25. Wilkas, Lenore R. "Automated Control of Monographic Series, and Interaction Between Acquisitions, and Cataloging in an Online Environment.” Serials Librarian 13 (Oct./Nov. 1987), 159-161.

26. McKay, Beatrice L., and Geer, Beverly. "Series Authority Records in an Integrated System: Enhancing Catalog Effectiveness.” Serials Review 21 (Winter 1995), 23-34.

27. Alessi, and Goforth. "Standing Orders and Approval Plans," 25-26.

28. Powell, Ronald R. Basic Research Methods for Librarians. 2nd ed. Norwood, N.J.: Ablex, 1991, p. 75.

29. Hamilton, Marsha. Conversation with the author, March 1998.

30. Lugg, Rick. E-mail to the author, February 1998.

31. Schatz, Bob. E-mail to the author, February 1998.

32. Lugg, Rick. E-mail.

33. Dorn, Knut. E-mail to the author, February 1998.

34. Library of Congress. Series Group. (1994).

35. Hawks, Carol Pitts. Letter to Sarah Thomas, Director for Cataloging, Library of Congress regarding The Ohio State University Libraries Acquisition Department’s response to LC series proposal (April 7, 1994). 